\title{
Minimizing Variance in Variable Renewable Energy Generation in Northern Europe
}

\author{
Koivisto, Matti Juhani; Cutululis, Nicolaos Antonio; Ekstrom, Jussi
}

Published in:

2018 IEEE International Conference on Probabilistic Methods Applied to Power Systems (PMAPS)

Link to article, DOI:

10.1109/PMAPS.2018.8440369

Publication date:

2018

Document Version

Peer reviewed version

Link back to DTU Orbit

Citation (APA):

Koivisto, M. J., Cutululis, N. A., \& Ekstrom, J. (2018). Minimizing Variance in Variable Renewable Energy Generation in Northern Europe. In 2018 IEEE International Conference on Probabilistic Methods Applied to Power Systems (PMAPS) IEEE. https://doi.org/10.1109/PMAPS.2018.8440369

\section{General rights}

Copyright and moral rights for the publications made accessible in the public portal are retained by the authors and/or other copyright owners and it is a condition of accessing publications that users recognise and abide by the legal requirements associated with these rights.

- Users may download and print one copy of any publication from the public portal for the purpose of private study or research.

- You may not further distribute the material or use it for any profit-making activity or commercial gain

- You may freely distribute the URL identifying the publication in the public portal 


\section{Minimizing Variance in Variable Renewable Energy Generation in Northern Europe}

\author{
Matti Koivisto \\ Department of Wind Energy \\ Technical University of Denmark \\ Roskilde, Denmark \\ mkoi@dtu.dk
}

\author{
Nicolaos Cutululis \\ Department of Wind Energy \\ Technical University of Denmark \\ Roskilde, Denmark \\ niac@dtu.dk
}

\author{
Jussi Ekström \\ Department of Electrical Engineering \\ Aalto University School of Electrical \\ Engineering \\ Espoo, Finland \\ jussi.ekstrom@aalto.fi
}

\begin{abstract}
The growing installations of variable renewable energy (VRE) sources, which are driven by weather patterns, can cause challenges to the operation and planning of power systems. This paper minimizes the variance of aggregate VRE generation based on the amount of different VRE technology types installed in different countries over a large geographical area. A mixture of offshore and onshore wind, and solar photovoltaic generation is considered. In the presented case study in Northern Europe, the optimized scenario provides a doubling of the expected annual VRE energy with a much lower increase in the aggregate VRE generation variability compared to other scenarios. The optimized scenario shows clearly the benefit of having a mixture of different VRE technologies with geographically highly spread installations.
\end{abstract}

Keywords-Optimization, renewable energy, solar, variance, wind.

\section{INTRODUCTION}

The installed capacities of variable renewable energy (VRE) sources have been growing rapidly and are expected to grow more in the future. VRE generation, which consists mostly of wind and solar power, is dependent on weather patterns and thus variable. This can cause challenges to the operation and planning of power systems compared to only having traditional generation (e.g., thermal and hydro) in the system.

Wind power variability modelling has been a topic of interest for several years [1]-[3]. The geographical distribution of wind installations has a significant effect on the aggregate wind generation. Increasing the geographical spread can decrease the variability of the aggregate generation significantly over a large geographical area [3]. Compared to wind, the geographical distribution has a lesser effect on the variability of solar photovoltaic (PV) generation [4]. However, a mixture of wind and solar PV can be very interesting when considering variability of aggregate VRE generation, as they are often negatively correlated [5]. The effect of this is discussed more in Section II.

As the geographical distribution of different VRE sources has an effect on the variability of the aggregate VRE generation, one can ask if the variability could be minimized. It has been shown that this can be done for the variance of the aggregate generation [3], [6]-[10]. In [6], [7], mean-variance portfolio optimization was used for optimizing wind farm locations in a single country. In [8], [9], similar optimization was carried out for several European countries. In [10], portfolio optimization was used to optimize the management of both wind and solar energy resources in Spain.

This paper models the effects of different VRE technology types and their geographical distribution on the aggregate VRE generation variance in Northern Europe. The approach is similar to [10], but applied on a larger geographical area covering multiple countries. The VRE technologies are split to onshore wind, offshore wind and solar PV. The inclusion of solar PV into the generation mix is an extension of modelling only wind in [3], [6]-[9]. Compared to [10], the separation of wind to onshore and offshore is an addition. 34 years of simulated hourly wind and solar PV generation data are used to estimate the mean vector and covariance matrix required in the variance minimization. In addition to minimizing the aggregate VRE generation variance, the full probability distribution of the resulting aggregate generation is studied.

The studied countries are Denmark (DK), Finland (FI), Norway (NO), Sweden (SE), Estonia (EE), Lithuania (LT), Latvia (LV), Germany (DE), Netherlands (NL) and Poland (PL). The starting point is the VRE installation situation in 2016. The expected annual VRE energy from these installations is estimated, and a doubling of the annual energy is implemented while minimizing the aggregate variance. Ambitious but feasible investments limits (assuming highly interconnected future) for the different countries are implemented in the optimization constraints. It is shown that optimizing both the mix of the different VRE technology types and their geographical distribution lowers the aggregate variance significantly compared to other scenarios.

In [9], the variance of hourly aggregate VRE generation ramp rates, rather than the overall variance, was minimized. Motivated by the analysis of residual load behavior in future scenarios in [11], where the additional ramping from VRE generation compared to load was considered modest in Nordic and Baltic countries, a decision to minimize the overall variance was taken in this paper. However, it will be shown that the optimized scenario shows also a reduced ramp rate variance.

This paper is structured as follows. Section II takes a theoretical look at the variance of aggregate VRE generation, and describes its minimization. Section III presents the VRE data used, and Section IV presents the resulting optimized scenario. Section V provides discussion on the assumptions 
taken and discusses possible future work. Section VI concludes the paper.

\section{MinimizIng VARIANCE OF AGGREGATE VRE GENERATION}

This section provides a theoretical look at the variance of aggregate VRE generation, and how it depends on the statistical properties of the different VRE sources. The minimization of the aggregate variance, and related assumptions, are then described.

\section{A. Variance of Aggregate VRE Generation}

Considering $k$ different sources of VRE generation, their aggregate generation at time $t$ is

$$
p_{t}=\sum_{i=1}^{k} w_{i} y_{i, t},
$$

where $w_{i}$ is the installed capacity (or weight) of source $i$, and $y_{i, t}$ is its standardized generation. A VRE source means, e.g., solar PV generation in DE or offshore wind generation in DK. Standardized generation means that $y_{i, t}$ get values between 0 and 1 , where 1 means that the source is generating at full installed capacity.

The variance of the aggregate VRE generation $p_{t}$ is

$$
\operatorname{Var}\left(p_{t}\right)=\sum_{i=1}^{k} w_{i}^{2} \sigma_{i}^{2}+2 \sum_{i \leq j \leq k} w_{i} w_{j} \sigma_{i} \sigma_{j} \rho_{i, j},
$$

where $\sigma_{i}^{2}=\operatorname{Var}\left(y_{i, t}\right)$ and $\rho_{i, j}=\operatorname{Cor}\left(y_{i, t}, y_{j, t}\right)$ [3]. As can be seen from (2), the variance of the aggregate VRE generation depends on the variances of the individual sources $\sigma_{i}^{2}$, and on the correlations between the sources $\rho_{i, j}$.

\section{B. Minimizing the Aggregate Variance}

In (2), the variables $\sigma_{i}$ and $\rho_{i, j}$ are mostly defined by meteorological behavior. In this paper, it is considered that those parameters do not change (this is discussed more in Section V) However, the weights $w_{i}$ can be optimized so that (2) is minimized. This means that the variance of the aggregate generation is minimized in relation to the installed capacities of the different VRE generation sources.

As can be seen in (2), increasing the share $w_{i}$ of a VRE source with high variance $\sigma_{i}^{2}$ makes the aggregate variance higher. Avoiding sources with high variance is, however, not the only concern in the minimization, as changing $w_{i}$ also affects the correlation part of (2). The minimization of (2) was carried out using Matlab function fmincon (Matlab R2016b, Optimization Toolbox [12]).

\section{Constraints}

\section{1) Expected Annual VRE Energy Generated}

It was chosen that each studied scenario (i.e., a set $w_{1}, \ldots$, $w_{k}$ ) should give the same expected annual VRE energy (assuming 8760 hours per year). This is given as a constraint in the $\boldsymbol{A x}=\boldsymbol{b}$ form as

$$
\left[\begin{array}{lll}
\mathrm{E}\left(y_{1, t}\right) & \ldots & \mathrm{E}\left(y_{k, t}\right)
\end{array}\right]\left[\begin{array}{c}
w_{1} \\
\vdots \\
w_{k}
\end{array}\right]=\frac{E_{\mathrm{a}}}{8760},
$$

where is the $E_{\mathrm{a}}$ is the expected annual VRE energy generated with installed capacities $w_{i}$ for the different VRE sources with expected values $\mathrm{E}\left(y_{i, t}\right)$. As $y_{i, t}$ are given as standardized generation, the expected values are the capacity factors of the different sources.

\section{2) Lower and Upper Bounds for the Weights}

It was considered that current VRE installations will not be decreased. Thus, the lower bounds of $w_{i}$ are the installed capacities of 2016; they are taken from the ENTSO-E Statistical Factsheet for 2016 [13].

Upper bounds of $w_{i}$ for wind installations are taken mostly from the WindEurope 2030 high scenario [14], which was considered to represent ambitious but still feasible installations for the different countries. However, for Baltic countries the onshore wind installation limits were increased to $2 \mathrm{GW}$. For offshore wind, a maximum limit of $5 \mathrm{GW}$ was set for NO, $2 \mathrm{GW}$ for FI and SE, and 1.2 GW for the Baltic countries.

For solar PV, the SolarPower Europe's medium scenario for 2021 was considered as the starting point [15]. However, to extend the horizon further into the future, a $50 \%$ increase was implemented. The results were used as the upper bounds for DE and NL. To allow for some solar investments also in the north, a $5 \mathrm{GW}$ limit for the Nordic countries and PL, and a $2 \mathrm{GW}$ limit for the Baltic countries were set for solar PV installations. The resulting lower and upper bounds for $w_{i}$ can be seen in Appendix C.

\section{VRE GENERATION DATA USED}

This section describes the VRE generation time series from which the statistical parameters required for (2) and (3) are estimated from. The most important aspects of these statistical characteristics are then described.

\section{A. 34 Years of Meteorological Reanalysis Data}

The VRE generation time series are simulated using the CorRES tool developed at DTU Wind Energy, which is based on meteorological data obtained from the mesoscale Weather Research and Forecasting (WRF) model [16]. The downscaling method presented in [17], [18] has been used to generate time series of, e.g., wind speed and irradiance. The simulations are a reanalysis of past weather, currently covering 34 years with hourly resolution. The analyzed countries are shown on a map in Fig. 1.

From the WRF model, hourly meteorological time series are obtained on a $10 \mathrm{~km} \mathrm{x} 10 \mathrm{~km}$ grid that covers the area of interest. This grid of data was used to create wind and solar PV generation time series for the different countries (installations were aggregated to closest grid points). For countries with wind generation installations, the existing locations were used. For countries without installations, e.g., offshore wind for NO, planned locations were used [19]. For solar PV, installations were assumed to be scattered throughout the countries, with more weight to the south for FI, NO and SE. The application of WRF reanalysis data in large-scale wind and solar PV generation simulation has been validated, e.g., in [20], [21]. 


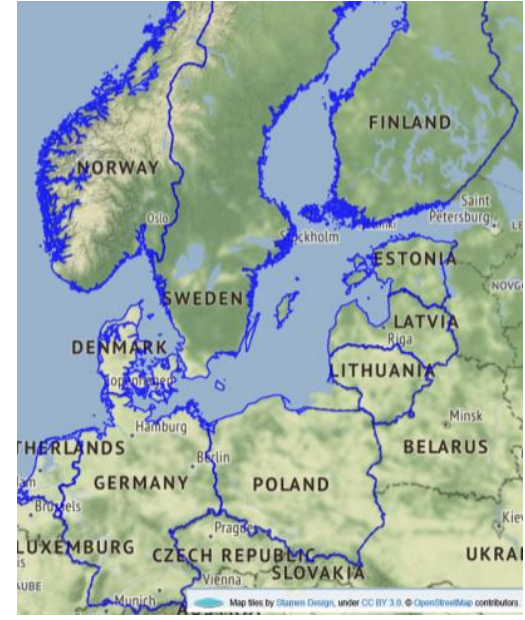

Fig. 1. Map of the analyzed countries. (C) EuroGeographics for the administrative boundaries.

\section{B. Statistical Characteristics of the Individual VRE Sources}

Descriptive statistics of the different VRE sources are given in Appendix A. A low relative standard deviation (RSD), which is standard deviation (SD) divided by the mean, shows which VRE sources are favorable for the minimization of (2) when looking only at the first part of the equation $\sum_{i=1}^{k} w_{i}^{2} \sigma_{i}^{2}$. It can be seen that offshore wind generation at the best locations, e.g., DK and NO are the most favorable sources. Solar PV are the least favorable sources when looking at only the RSD values.

\section{Correlations Between the VRE Sources}

Average correlations between the different VRE types are shown in Table I, and more detailed numbers are given in Appendix A. Wind generations in the different countries are on average quite correlated, but correlation decreases as distance between the countries increases. Solar PV generations in the different countries are always highly correlated.

The most interesting case considering the correlations are the slightly negative correlations between solar PV and wind generation. It can be seen in Appendix A that the correlations between all solar and wind generation sources are negative. This allows a combination of solar and wind to decrease the variance of the aggregate VRE generation (2), as the second part $2 \sum_{i \leq j \leq k} w_{i} w_{j} \sigma_{i} \sigma_{j} \rho_{i, j}$ can be even negative.

TABLE I. AVERAGE CORRELATIONS BETWEEN THE VRE TYPES

\begin{tabular}{|c|c|c|c|}
\hline & Onshore wind & Offshore wind & Solar PV \\
\hline Onshore wind & 0.414 & 0.406 & -0.163 \\
\hline Offshore wind & 0.406 & 0.337 & -0.137 \\
\hline Solar PV & -0.163 & -0.137 & 0.903 \\
\hline
\end{tabular}

\section{RESUlTS FOR THE CASE STUDY}

This section shows the resulting optimized scenario and compares it to other scenarios.

\section{A. The Scenarios}

The weights for "Today" are taken from the ENTSO-E Statistical Factsheet for 2016 [13]. The scenario called "Today doubled" is created by doubling all the installations in the today's scenario, which leads to a doubling of the expected annual VRE energy.

The "Optimized" scenario is created by minimizing the variance of the aggregate VRE generation (2), while respecting the constraints specified in Section II C, with the target of getting double the annual VRE energy. To study the effects of having both wind and solar in the generation mix, an "Only wind" scenario is also created; it is like the "Optimized" scenario, but with zero weights for solar PV sources.

\section{B. General comparisons}

The optimized frontier in Fig. 2 shows that a small increase of the expected annual VRE energy from "Today" can be achieved with only a small increase in the SD of the aggregate VRE generation. However, as the upper bounds for $w_{i}$ start to affect more, the aggregate SD starts to increase more rapidly when annual VRE energy increases.

As can be seen Table II, in the "Today doubled" scenario the SD of the aggregate VRE generation is double compared to "Today" (because it is simply a scaled-up version of "Today"). In the "Optimized" scenario, the doubling of the annual VRE energy is achieved by having a $21 \%$ lower SD of the aggregate VRE generation than in "Today doubled".

In the "Only wind" scenario, the aggregate VRE generation SD is notably (20\%) higher than in the "Optimized" scenario, which shows the significance of having both solar and wind in the future VRE generation mix.

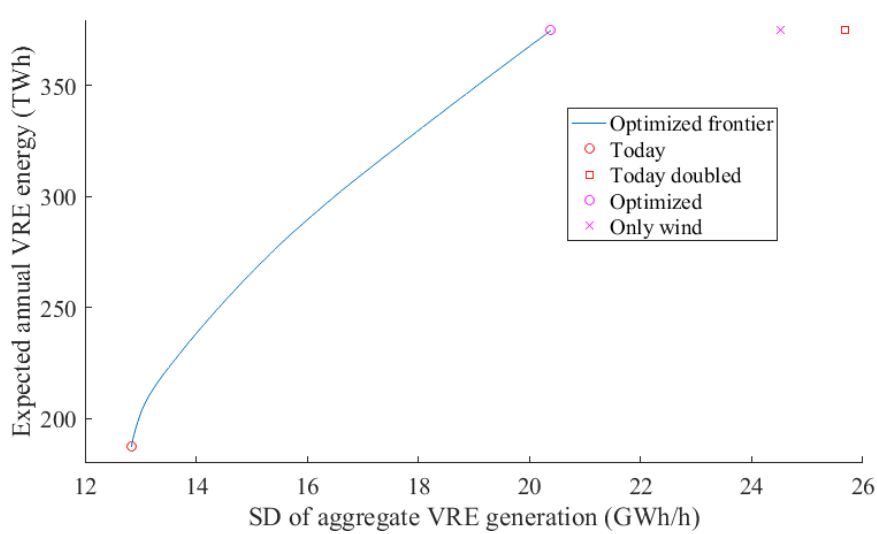

Fig. 2. The optimized frontier from today's annual VRE energy to its doubling, and how the different scenarios compare to it.

TABLE II. OVERALL RESULtS OF THE SCENARIOS

\begin{tabular}{|c|c|c|c|c|c|}
\hline Scenario & $\begin{array}{c}\text { SD of } \\
\text { aggregate } \\
(\mathbf{G W h} / \mathbf{h})\end{array}$ & $\begin{array}{c}\text { Annual } \\
\text { VRE } \\
\text { energy } \\
\text { (TWh) }\end{array}$ & $\begin{array}{l}\text { Onshore } \\
\text { wind } \\
\text { share }\end{array}$ & $\begin{array}{l}\text { Offshore } \\
\text { wind } \\
\text { share }\end{array}$ & $\begin{array}{c}\text { Solar } \\
\text { PV } \\
\text { share }\end{array}$ \\
\hline Today & 12.8 & 187 & $67 \%$ & $11 \%$ & $22 \%$ \\
\hline $\begin{array}{l}\text { Today } \\
\text { doubled }\end{array}$ & 25.7 & 375 & $67 \%$ & $11 \%$ & $22 \%$ \\
\hline Optimized & 20.4 & 375 & $51 \%$ & $30 \%$ & $19 \%$ \\
\hline Only wind & 24.5 & 375 & $56 \%$ & $44 \%$ & $0 \%$ \\
\hline
\end{tabular}




\section{The Optimized Weights}

As can be seen in Table II, in the "Optimized" scenario the share of offshore wind is greater than in "Today doubled". However, the optimization does not simply maximize the amount of offshore wind everywhere, as can be seen Appendices $\mathrm{B}$ and $\mathrm{C}$; both the onshore wind and solar PV installations are also increased.

Fig. 3 shows a country-wise aggregated view of the optimized VRE installations in the "Today" and "Optimized" scenarios. For DE, which already has a lot of VRE generation installed, the optimization puts no more installations. The optimization chooses to put much of the additional VRE installations into countries further away from the areas with high VRE installations today, such as FI, NO and EE.

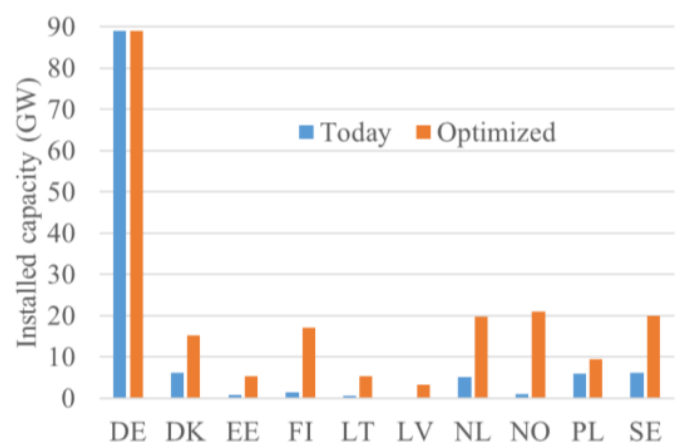

Fig. 3. The sums of installed VRE generation capacities in the different countries.

\section{A Look at the Full Probability Distributions}

In addition to looking only at the first and second statistical moments, which fully specify (2) and (3), Fig. 4 shows the full probability distribution functions (PDFs) of aggregate VRE generation in the scenarios "Today doubled" and "Optimized". In addition to lower SD, the optimized scenario has also significantly reduced aggregate VRE generation $5^{\text {th }}$ and $95^{\text {th }}$ percentiles, as can be seen in Table III.

Ramp rates were not considered in the minimization of (2) at all. However, Fig. 5 shows that the "Optimized" scenario has also lower aggregate hourly ramping (i.e., variability of the $1^{\text {st }}$ difference of aggregate hourly generation) than the "Today doubled" scenario. Table III shows that both ramp rate SD and the $5^{\text {th }}$ and $95^{\text {th }}$ percentiles are lower.

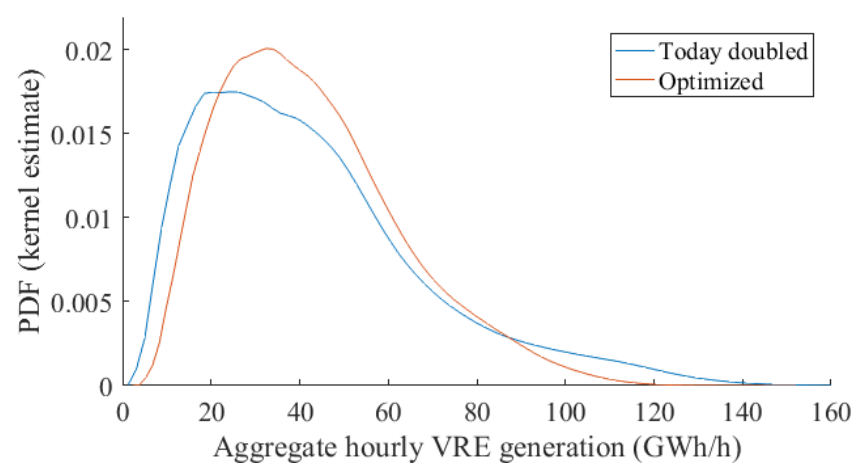

Fig. 4. Estimated PDFs of the aggregate VRE generation for the "Today doubled" and "Optimized" scenarios

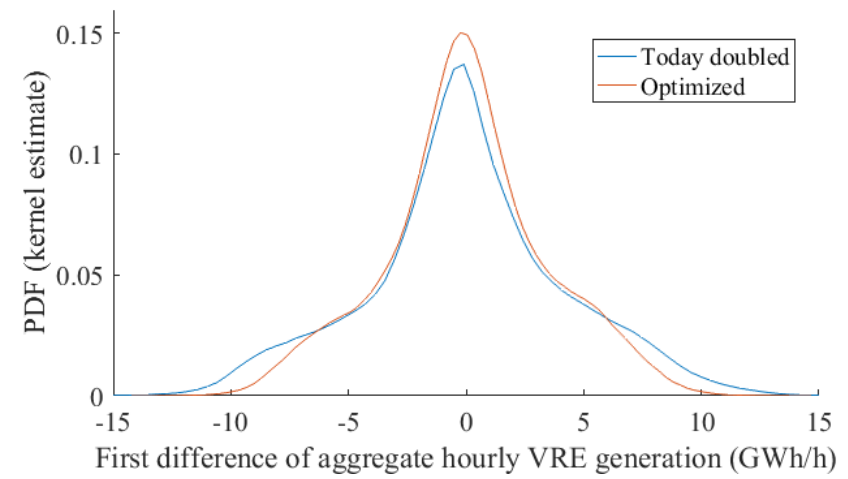

Fig. 5. Estimated PDFs of the hourly ramp rates of aggregate VRE generation for the "Today doubled" and "Optimized" scenarios.

TABLE III. STATISTICS FOR THE SCENARIOS

\begin{tabular}{|c|c|c|c|}
\hline Scenario & $\begin{array}{c}\mathbf{5}^{\text {th }} \text { and } 95^{\text {th }} \\
\text { percentiles } \\
(\mathbf{G W h} / \mathbf{h})\end{array}$ & $\begin{array}{c}\text { SD of } \mathbf{1}^{\text {st }} \\
\text { difference } \\
(\mathbf{G W h} / \mathbf{h})\end{array}$ & $\begin{array}{c}\mathbf{5}^{\text {th }} \text { and } 95^{\text {th }} \\
\text { percentiles of } \mathbf{1}^{\text {st }} \\
\text { difference }(\mathbf{G W h} / \mathbf{h})\end{array}$ \\
\hline $\begin{array}{c}\text { Today } \\
\text { doubled }\end{array}$ & $10.9,95.6$ & 4.31 & $-7.65,7.51$ \\
\hline Optimized & $15.0,82.0$ & 3.53 & $-6.23,6.15$ \\
\hline
\end{tabular}

\section{DISCUSSION}

It was assumed that only the weights $w_{i}$ can be used in the minimization of (2), and that the statistical VRE parameters $\sigma_{i}^{2}$ and $\rho_{i, j}$, and $\mathrm{E}\left(y_{i, t}\right)$ in (3), remain the same in the future. This assumes, e.g., that the future wind installations have similar capacity factors to today and that additional installations in the countries do not change the SDs shown in Appendix A.

Assuming that countries experience relatively similar capacity factor development in the future, the optimal shares of wind in the different countries should remain relatively similar to the ones showed in Appendix B. However, the optimal shares between wind and solar PV can be quite different when capacity factors change. The changing capacity factors will be considered in future research.

In the numbers shown in Appendix A, no clear difference in SD was noticed between countries with currently high or low shares of onshore wind generation (the geographical sizes of the countries seem to explain most of the differences). For offshore wind, for countries with currently no installations, a few planned projects were modelled to make them comparable to countries with offshore wind installed today. For solar PV, installations were assumed to be geographical scattered for all countries (this represents mostly residential solar PV installations). These notions give some justification that the statistical parameters estimated from today's data are also representative of the future.

Grid constraints were not considered in the analysis. While the per-country installation limits were considered feasible, grid constraints should be considered in future work. Also, dynamic studies of the optimized scenario need to be carried out before its feasibility can be verified.

An important consideration in future work is to include load in the analysis, and to model the variability of the residual load [11]. This is important as the residual load is what the non-VRE 
generation needs to fulfill (or it needs to be handled by demandside management or transmission to other countries).

\section{CONCLUSION}

This paper has shown a method to minimize the variance of aggregate VRE generation based on the amount of different VRE technology types installed in different countries. A case study in Northern Europe was presented with the aim to double the expected annual VRE energy. It was shown that the optimized scenario can provide this with a $21 \%$ lower increase in the aggregate VRE generation SD compared to if the doubling would be achieved by simply scaling up the current installations.

It was shown that the optimized scenario uses a mixture of offshore wind, onshore wind and solar PV. Although offshore wind has the lowest RSD in the individual countries, the negative correlations between solar PV and wind generation make the case for having both solar and wind in the future VRE generation mix. This was emphasized by showing that without solar generation, the SD in the optimized scenario would be $20 \%$ higher. A look at the VRE installations in the different countries showed the benefit of having VRE installations more geographically spread compared to today.

The presented optimized scenario is based on a minimization of a single statistical parameter, namely variance of the aggregate VRE generation. However, it was shown that the resulting optimized scenario shows also significantly reduced probabilities of very high and low aggregate VRE generation and reduced ramp rates compared to simply scaling up the today's installations.

The results highlight the importance of considering larger geographical regions than single countries when planning future power and energy systems. Also, a mixture of VRE technologies should be considered. Although the locations or types of future VRE installations cannot be forced, e.g., market structures and policies may be planned in a way that they incentivize future VRE installations that lower the variability of the aggregate generation.

As VRE generation is moving away from subsidies, market prices will affect generators more directly. In addition to maximizing annual energy generation, the correlations to other VRE generations can become an important consideration as spot market prices vary according to the overall generation available to the market. To quantify this, the presented simulations will be further analyzed using energy system models. Such modelling will also consider required transmission investments.

\section{ACKNOWLEDGMENT}

The authors would like to acknowledge support from the Flex4RES (Nordic Energy Research) and NSON-DK (ForskEL) projects.

\section{REFERENCES}

[1] G. Papaefthymiou and D. Kurowicka, "Using copulas for modeling stochastic dependence in power system uncertainty analysis," IEEE Transaction on Power Systems, vol. 24, no. 1, pp. 40-49, February 2009.

[2] D. Villanueva, A. Feijóo, and J. L. Pazos, "Simulation of correlated wind speed data for economic dispatch evaluation," IEEE Transactions on Sustainable Energy, vol. 3, no. 1, January 2012.
[3] M. Koivisto, J. Ekström, J. Seppänen, I. Mellin, J. Millar, and L. Haarla, "A statistical model for comparing future wind power scenarios with varying geographical distribution of installed generation capacity," Wind Energy, vol. 19, pp. 665-679, May 2016.

[4] J. Ekström, M. Koivisto, J. Millar, I. Mellin, and M. Lehtonen, “A statistical approach for hourly photovoltaic power generation modeling with generation locations without measured data," Solar Energy, vol. 132, pp. 173-187, 2016.

[5] J. Ekström, M. Koivisto, I. Mellin, R. J. Millar and M. Lehtonen “A Statistical Model for Hourly Large-Scale Wind and Photovoltaic Generation in New Locations", IEEE Transactions on Sustainable Energy, vol. 8, no. 4, pp. 1383-1393 October 2017.

[6] F. J. Santos-Alamillos, N. S. Thomaidis, J. Usaola-García d, J. A. RuizArias, and D. Pozo-Vazquez, "Exploring the mean-variance portfolio optimization approach for planning wind repowering actions in Spain", Renewable Energy, vol. 106, pp., 335-342, June 2017.

[7] C. J. Joubert, and H. J. Vermeulen, "Optimisation of Wind Farm Location Using Mean-Variance Portfolio Theory and Time Series Clustering", IEEE International Conference on Power and Energy, June 2016, Melaka, Malaysia.

[8] C. Tejeda, C. Gallardo, M. Domínguez, M. Á. Gaertner, C, Gutierrez, M. de Castro, "Using wind velocity estimated from a reanalysis to minimize the variability of aggregated wind farm production over Europe", Wind Energy, Early view article, 2017.

[9] F. Roques, C. Hirou, M. Saguan, "Optimal wind power deployment in Europe-A portfolio approach”, Energy Policy, vol. 38, pp. 3245-3256, 2010.

[10] N. S. Thomaidis, F. J. Santos-Alamillos, D. Pozo-Vázquez, J. UsaolaGarcía, Optimal management of wind and solar energy resources, Computers \& Operations Research, vol. 66, pp. 284-291, February 2016.

[11] M. Koivisto, P. Sørensen, P. Maule; E. Nuño, "Needs for Flexibility Caused by the Variability and Uncertainty in Wind and Solar Generation in 2020, 2030 and 2050 Scenarios", DTU Wind Energy.

[12] Matlab Optimization Toolbox Documentation: se.mathworks.com/help/optim/index.html (referenced December 22, 2017)

[13] ENTSO-E Statistical Factsheets webpage: https://www.entsoe.eu/publications/statistics/statisticalfactsheet/Pages/default.aspx (referenced December 22, 2017)

[14] WindEurope: Wind energy in Europe: Scenarios for 2030: https://windeurope.org/wp-content/uploads/files/aboutwind/reports/Wind-energy-in-Europe-Scenarios-for-2030.pdf (referenced January $25^{\text {th }}, 2018$ ).

[15] SolarPower Europe's Global Market Outlook 2017-2021: http://www.solarpowereurope.org/reports/global-market-outlook-2017/ (referenced January $25^{\text {th }}, 2018$ ).

[16] W. Skamarock, J. Klemp, J. Dudhia, D. Gill, D. Barker, M. Duda, X. Huang, W. Wang and J. Powers, "description of the advanced research WRF version 3,” Boulder, Colorado, USA, 2008.

[17] A. N. Hahmann, D. Rostkier-Edelstein, T. T. Warner, F. Vandenberghe, Y. Liu, R. Babarsky and S. P. Swerdlin, "A Reanalysis System for the Generation of Mesoscale Climatographies," Journal of Applied Meteorology and Climatology, pp. 954-972, 2010.

[18] A. N. Hahmann, C. L. Vincent, A. Peña, J. Lange and C. B. Hasager, "Wind climate estimation using WRF model output: method and model sensitivities over the sea," International Journal of Climatology, vol. 35 , no. 12, pp. 3422-3439, October 2015.

[19] 4C offshore wind farm database: http://www.4coffshore.com/windfarms/ (referenced January $25^{\text {th }}, 2018$ ).

[20] E. Nuño, P. Maule, A. Hahmann, N. Cutululis, P. Sørensen, I. Karagali, "Simulation of transcontinental wind and solar PV generation time series," Renewable Energy, vol. 118, pp. 425-436, April 2018.

[21] M. Marinelli, P. Maule, A. N. Hahmann, O. Gehrke, P. B. Nørgård and N. A. Cutululis, "Wind and Photovoltaic Large-Scale Regional Models for Hourly Production Evaluation," IEEE Transactions on Sustainable Energy, vol. 6, no. 3, pp. 916-923, 2015. 
APPENDIX A: DESCRIPTIVE STATISTICS OF VRE GENERATION

\begin{tabular}{|c|c|c|c|c|c|c|c|c|c|c|c|c|c|c|c|c|c|c|c|c|c|c|c|c|c|c|c|c|c|c|}
\hline & \multicolumn{10}{|c|}{ Onshore wind } & \multicolumn{10}{|c|}{ Offshore wind } & \multicolumn{10}{|c|}{ Solar PV } \\
\hline & DE & DK & $\mathbf{E E}$ & FI & LT & LV & NL & NO & PL & SE & DE & DK & \begin{tabular}{|l|l} 
EE & I \\
\end{tabular} & FI & LT & LV & $\mathrm{NL}$ & NO & PL & SE & DE & DK & $\mathbf{E E}$ & FI & LT & LV & NL & NO & PL & SE \\
\hline Mean & 0.19 & 0.24 & 0.26 & 0.25 & 0.24 & 0.26 & 0.26 & 0.29 & 0.24 & 0.26 & 0.39 & 0.43 & \begin{tabular}{|l|} 
\\
\end{tabular} & 0.30 & 0.36 & 0.31 & 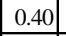 & 0.40 & 0.36 & 0.34 & 0.11 & 0.11 & 0.12 & 0.09 & 0.12 & 0.12 & 0.10 & 0.10 & 0.10 & 0.11 \\
\hline SD & \begin{tabular}{|l|} 
\\
\end{tabular} & 0.24 & 0.24 & 0.21 & 0.24 & 0.26 & 0.25 & 0.19 & 0.21 & 0.18 & \begin{tabular}{|l|} 
\\
\end{tabular} & 0.30 & \begin{tabular}{|l|} 
\\
0.30 \\
\end{tabular} & 0.27 & 0.33 & 0.31 & \begin{tabular}{|l|}
0.31 \\
\end{tabular} & \begin{tabular}{|l|} 
\\
\end{tabular} & 0.31 & 0.26 & 0.16 & \begin{tabular}{|l|l|} 
& 0.18 \\
\end{tabular} & 0.19 & 0.14 & 0.18 & 0.18 & 0.15 & 0.15 & 0.14 & 0.16 \\
\hline RSD & 0.94 & \begin{tabular}{|l|}
0.97 \\
\end{tabular} & 0.93 & 0.86 & 1.02 & 1.01 & \begin{tabular}{|l|}
0.96 \\
\end{tabular} & \begin{tabular}{|c|} 
\\
\end{tabular} & 0.86 & 0.70 & 0.79 & \begin{tabular}{|l|}
0.70 \\
\end{tabular} & 1.03 & \begin{tabular}{|l|}
0.89 \\
\end{tabular} & \begin{tabular}{|l|} 
\\
\end{tabular} & 1.01 & \begin{tabular}{|l|}
0.78 \\
\end{tabular} & \begin{tabular}{|l|}
0.71 \\
\end{tabular} & 0.88 & 0.77 & 1.44 & \begin{tabular}{|l|}
1.54 \\
\end{tabular} & \begin{tabular}{|c|}
1.57 \\
\end{tabular} & 1.61 & 1.54 & 1.54 & \begin{tabular}{|l|}
1.48 \\
\end{tabular} & 1.53 & 1.45 & 1.54 \\
\hline
\end{tabular}

\begin{tabular}{|c|c|c|c|c|c|c|c|c|c|c|c|c|c|c|c|c|c|c|c|c|c|c|c|c|c|c|c|c|c|c|c|}
\hline & & \multicolumn{10}{|c|}{ nd } & \multicolumn{10}{|c|}{ Offshore } & \multicolumn{10}{|c|}{$\operatorname{lar} \mathbf{P V}$} \\
\hline & & & & EE & FI & $\overline{L T}$ & & & NO & 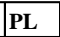 & & DE & n & $\mathbf{E E}$ & III & LT & $\mathrm{V}$ & $L$ & & PL & $\mathbf{E}$ & DE & DK & $\mathbf{E E}$ & FI & LT & $\mathbf{L V}$ & $\mathrm{NL}$ & 0 & PL & SE \\
\hline \multirow{10}{*}{ 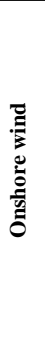 } & & & 66 & 5 & & & & & \begin{tabular}{|l|}
0.26 \\
\end{tabular} & & & & 61 & 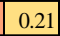 & & & & & 07 & 50 & 32 & 21 & 0.22 & 0.22 & 0.23 & 0.22 & 2 & 21 & -0.21 & 0.20 & -0.2 \\
\hline & & & & & & & & & .45] & & & & & 25 & & & & & 14 & 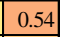 & 43 & 07. & 11 & 10 & 1 & -0.11 & .10 & 07 & 1.11 & .07 & 1 \\
\hline & EF & 25 & & & & & & & - & 0 & & & 23 & 1 & & & & & & .36 & & $t$ & \begin{tabular}{|l|}
-0.14 \\
\end{tabular} & 18 & & 16 & 16 & $12-$ & & .13 & \\
\hline & FI & 14 & 8 & & & 0 & & & 37] & 0.18 & 0.58 & 12 & 16 & 6 & 87 & & 33 & 10 & 29] & 18 & 49 | & ti & \begin{tabular}{|c|}
-0.11 \\
\end{tabular} & 0.13 & ] & -0.1 & 0.12 & $09-$ & 0.14 & 0.10 & 1 \\
\hline & LT & 40 & 9 & & & & & & .22 & 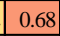 & 51 & 0.29 & \begin{tabular}{|l|l|}
0.35 \\
\end{tabular} & 56 & 22 & 36 & 76 & 23 & 0.08 & \begin{tabular}{|l|}
0.63 \\
\end{tabular} & 40 & \begin{tabular}{|c|}
-0.14 \\
\end{tabular} & $\mid-0.15$ & \begin{tabular}{|l|l|}
-0.18 \\
\end{tabular} & \begin{tabular}{|c|}
-0.18 \\
\end{tabular} & -0.18 & 18 & 0.14 & -0.16 & -0.15 & .1 \\
\hline & $\mathbf{L V}$ & 5 & 9 & & 36 & & & & 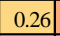 & 57 & & & 34 & 74 & 32 & 81 & 38 & 21 & 13 & 57 & 18 & 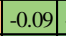 & \begin{tabular}{|c|}
-0.11 \\
\end{tabular} & 15 & 16 & -0. & 0.14 & -09|- & -0.12 & -0.10 & .1 \\
\hline & $\mathbf{N L}$ & 30 & & & & 0.26 & & & 25 & 42 & & 0.72 & \begin{tabular}{|l|}
0.50 \\
\end{tabular} & \begin{tabular}{|l|}
0.15 \\
\end{tabular} & & & $24 \mid$ & 34] & 88 & 32 & t & & \begin{tabular}{|l|l|}
-0.19 \\
\end{tabular} & 17 & \begin{tabular}{|c|}
0.19 \\
\end{tabular} & $\mid-0.17$ & .17 & + & & $-0.1 \%$ & .1 \\
\hline & \begin{tabular}{|l|} 
NO \\
\end{tabular} & & & & & 0.22 & & & & 22 & & 35] & \begin{tabular}{|l|}
0.41 \\
\end{tabular} & 24 & כग & & 22 & 28 & 0.70 & 21 & t & \begin{tabular}{|c|}
-0.13 \\
\end{tabular} & $|-0.17|$ & $|-0.18|$ & \begin{tabular}{|c|}
-0.22 \\
\end{tabular} & {$[-0.1$} & .18 & .14 & -0. & -0. & 0.2 \\
\hline & $\mathbf{P L}$ & & & & 18 & 68 & & & \begin{tabular}{|l|l|} 
\\
\end{tabular} .2 & & & $+1 /$ & 53 & 35 & 15 [ & & 54 & & .07 & 78| & t & & $\mid-0.20$ & 231 & 3. & -0. & 2. & & & -0.2 & 0.2 \\
\hline & \begin{tabular}{|l|}
$\mathbf{S E}$ \\
\end{tabular} & & & & & 51 & & & 0.52 & & & & 53] & & 55] & & & & 0.32 & 2 & .77| & . & - & 20 & 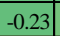 & -0.19 & & .15 & -0. & 0.16 & 0.2 \\
\hline \multirow{10}{*}{ 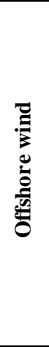 } & E & 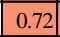 & & & & 29 & & & 0.35 & 0.47 & & & & & 10] & & & & 11 | & 43 & 31 & 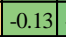 & \begin{tabular}{|l|l}
-0.16 \\
\end{tabular} & \begin{tabular}{|l|l|}
-0.15 \\
\end{tabular} & 5. & -0. & 0.15 & 0.14 & -0. & -0.11 & 0.1 \\
\hline & DK & 4 & 36 & & 16 & 35 & & & 0.41 & 0.53 & & & & & & & & & 0.13 & & \begin{tabular}{|l|l|}
0.43 \\
\end{tabular} & 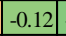 & \begin{tabular}{|l}
-0.15 \\
\end{tabular} & \begin{tabular}{|c|}
-0.14 \\
\end{tabular} & 4 & -0. & & 0.14 & -0. & -0.1 & 0.1 \\
\hline & $\mathbf{E E}$ & 0.21 & 7 & & 0.46 & 0.56 & & & 0.24 & 0.35 & & 0.18 & 0.22 & & & 0.34 & 65 & & 0.15 & 0.35 & \begin{tabular}{|l|}
0.47 \\
\end{tabular} & 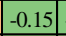 & \begin{tabular}{|c|}
-0.16 \\
\end{tabular} & 19] & -0.20 & -0.1 & -0.18 & 0.13 & -0 . & -0. & 0.1 \\
\hline & FI & 0.11 & 16 & & \begin{tabular}{|l|l} 
\\
\end{tabular} & 0.22 & & & 0.35 & 0.15 & 55 & 10 & 16 & & & & 33 & & 29 & 16 & \begin{tabular}{|l|}
0.47 \\
\end{tabular} & + & \begin{tabular}{|l|}
-0.1 \\
\end{tabular} & 0.12 & 5 & \begin{tabular}{|l} 
\\
\end{tabular} & 0.11 & 0.09 & -0. & -0. & 0.1 \\
\hline & LT & 37 & 1 & & & 0.86 & & & 0.2 & 0. & & & 36 & \begin{tabular}{|l|l|}
0.54 \\
\end{tabular} & & & & & & & 41 & & \begin{tabular}{|l|l|}
-0.17 \\
\end{tabular} & 19 & 3] & -0 & & & -0. & -0.16 & \\
\hline & $\mathbf{L V}$ & 34 & T & & & 0.76 & & & \begin{tabular}{|l|}
0.22 \\
\end{tabular} & 0.54 & & & 34 & 0.65 & & & & & & & I & 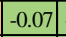 & -0.06 & 0.12 & 1 & -1 & -0.11 & & -0 . & -0.08 & 0.1 \\
\hline & $\mathbf{N L}$ & \begin{tabular}{|l|}
0.67 \\
\end{tabular} & 53 & & & 0.23 & & & \begin{tabular}{|l|}
0.28 \\
\end{tabular} & 0.36 & 26 & 0.86 & \begin{tabular}{|l|}
0.57 \\
\end{tabular} & \begin{tabular}{|l|l|}
0.14 \\
\end{tabular} & & 0.22 & & & & T & T & 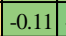 & -0.1 & 0.14 & \begin{tabular}{|c|}
0.15 \\
\end{tabular} & -0.1 & & & -0 & $\begin{array}{l}-0.1 \\
\end{array}$ & 0.1 \\
\hline & \begin{tabular}{|l|} 
NO \\
\end{tabular} & & 4 & & & 0. & & & \begin{tabular}{|l|}
0.70 \\
\end{tabular} & $\begin{array}{l}0.07 \\
\end{array}$ & 32 & & \begin{tabular}{|l|}
0.13 \\
\end{tabular} & 5 & & & \begin{tabular}{|l|l|}
0.13 \\
\end{tabular} & & & & & -0 & -0. & -0.12 & & & & & & & 0.1 \\
\hline & PL & & & & & 0. & & 4 & \begin{tabular}{|l|l|}
0.21 \\
\end{tabular} & 78 & 52 & 3 & \begin{tabular}{|l|l|}
0.54 \\
\end{tabular} & \begin{tabular}{|l|}
0.35 \\
\end{tabular} & 6] & 4 & 0.54 & 30] & \begin{tabular}{|l|l|}
0.07 \\
\end{tabular} & & 3. & \begin{tabular}{|c|}
-0.13 \\
\end{tabular} & It & 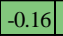 & -0.16 & & .116] & .12 & & -0.14 & .1 \\
\hline & SE & & & & & 0. & & & 4 & & & & \begin{tabular}{|l|}
0.43 \\
\end{tabular} & & & 1 & 4] & & \begin{tabular}{|l|}
0. \\
\end{tabular} & & & & -1 & 15 & & & & & & & .1 \\
\hline \multirow{10}{*}{ 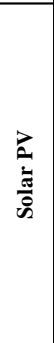 } & DE & & & & & 14] & & & \begin{tabular}{|c|}
-0.13 \\
\end{tabular} & & & & $\mid-0.12$ & & 9] & 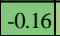 & 77 & & 77| & 13 & & & & + & & & & & & & \\
\hline & \begin{tabular}{|l|} 
DK \\
\end{tabular} & 22 & 111 & & -0.11 & -0.15 & & 19 & \begin{tabular}{|c|}
-0.17 \\
\end{tabular} & + & \begin{tabular}{|c|}
-0.18 \\
\end{tabular} & 16 & \begin{tabular}{|l|}
-0.15 \\
\end{tabular} & 16 & -0.11 & \begin{tabular}{|c|}
-0.17 \\
\end{tabular} & -1 & 15 & \begin{tabular}{|l|}
-0.10 \\
\end{tabular} & \begin{tabular}{|l|}
-0.14 \\
\end{tabular} & $|-0.13|$ & & & 0.91 & 7 & & 91 & & & & 0.9 \\
\hline & $\mathbf{E E}$ & 0.22 & 10 & & $\mid-0.13$ & $\mid-0.18$ & & & \begin{tabular}{|c|}
-0.18 \\
\end{tabular} & & 0.20 & \begin{tabular}{|l|}
-0.15 \\
\end{tabular} & \begin{tabular}{|c|}
-0.14 \\
\end{tabular} & \begin{tabular}{|l|}
-0.19 \\
\end{tabular} & -0.12 & -0. & 12 & -0. & \begin{tabular}{|l|}
-0.12 \\
\end{tabular} & \begin{tabular}{|c|}
-0.16 \\
\end{tabular} & \begin{tabular}{|c|}
-0.15 \\
\end{tabular} & $90 \mid$ & & & 0.91 & & 98| & & & 93 & \\
\hline & FI & 0.23 & 13 & & $\mid$\begin{tabular}{|c|}
-0.17 \\
\end{tabular} & \begin{tabular}{|l|l|}
-0.18 \\
\end{tabular} & 16 & 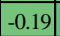 & $\mid-0.22$ & \begin{tabular}{|l|} 
\\
\end{tabular} & 0.23 & $\begin{array}{ll}0.16 \\
\end{array}$ & \begin{tabular}{|c|}
-0.14 \\
\end{tabular} & $\mid-0.20$ & -0.15 & \begin{tabular}{|c|}
-0.18 \\
\end{tabular} & 11 & -0.15 & \begin{tabular}{|c|}
-0.14 \\
\end{tabular} & \begin{tabular}{|l|l|}
-0.16 \\
\end{tabular} & -0.17 & 85 & \begin{tabular}{|l|}
0.87 \\
\end{tabular} & 91 & & & .90| & 75 & & 87 & \\
\hline & LT & 2 & .11 & & -0.12 & 0.18 & & -0 & 0.17 & -0.22 & -0.1 & -0.14 & 0.12 & -0 & $-0.11]$ & -0.17 & -0.08 & -0. & \begin{tabular}{|l|l|}
-0.10 \\
\end{tabular} & - & -0 & & & & 92 & & 0.5 & & & & \\
\hline & $\mathrm{LV}$ & -0.2 & 0.10 & & -0.12 & $|-0.18|$ & & -0. & \begin{tabular}{|c|}
-0.18 \\
\end{tabular} & -0.2 & -0. & -0. & 0.14 & & -0.1 & -0.1 & & & \begin{tabular}{|l|}
-0.11 \\
\end{tabular} & -1 & 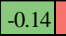 & & & & 0.90 & & & & & & \\
\hline & NI & & & & & $|-0.14|$ & & & \begin{tabular}{|l|} 
\\
\end{tabular} & & -0. & & 4] & & & -0. & & & -0. & -1 & & & & & & & & & & & \\
\hline & NO & & & & & $\mid-0.16$ & & & -0. & & 0 & & 7 & & & & & & -0. & & & & & & & & & & & & \\
\hline & PL & & -0.07 & & & 0.1 & & & -0 & & & & 0.1 & -0 & & & & & -0. & & & & & & & & & & & & \\
\hline & & & & & & & & & & & & & & & & & & & & & & & & & & & & & & 00 & \\
\hline
\end{tabular}

Some important statistics for the aggregate variance minimization are colored: green means generally favorable when looking at the variability of the aggregate VRE generation.

APPENDIX B: WEIGHTS IN THE SCENARIOS

\begin{tabular}{|c|c|c|c|c|c|c|c|c|c|c|c|c|c|c|c|c|c|c|c|c|c|c|c|c|c|c|c|c|c|c|}
\hline & \multicolumn{10}{|c|}{ Onshore wind } & \multicolumn{10}{|c|}{ Offshore wind } & \multicolumn{10}{|c|}{ Solar PV } \\
\hline $\begin{array}{c}\text { Installed } \\
\text { neration (GW) }\end{array}$ & DE & $\mathbf{K}$ & $\mathbf{E E}$ & FI & LT & LV & 1 & $\mathbf{N}$ & $\mathbf{P}$ & SE & \begin{tabular}{|l|l} 
DE & I
\end{tabular} & DK & $\mathbf{E E}$ & \begin{tabular}{|l|l|} 
FI & I \\
\end{tabular} & \begin{tabular}{l|l}
$\mathbf{L T}$ & $\mathbf{L}$
\end{tabular} & LV & NL & F & PL & SE & DE & DK & $\mathbf{E E}$ & \begin{tabular}{l|l} 
FI & I
\end{tabular} & \begin{tabular}{l|l} 
LT & L
\end{tabular} & LV & NL & NO & PL & SE \\
\hline 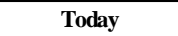 & 45.0 & & 0.4 & \begin{tabular}{|l|}
1.4 \\
\end{tabular} & 0.4 & 0.1 & 3.5 & 0.9 & 57 & 60 & \begin{tabular}{|l|l|}
4.1 & 1 \\
\end{tabular} & \begin{tabular}{l|l|l|}
1.3 & \\
\end{tabular} & \begin{tabular}{|l|l|l|}
0.0 & 0 \\
\end{tabular} & \begin{tabular}{l|l|}
0.0 & 0 \\
\end{tabular} & \begin{tabular}{l|l}
0.0 & 0. \\
\end{tabular} & \begin{tabular}{l|l}
0.0 & 0 \\
\end{tabular} & 0.6 & \begin{tabular}{|l|l|}
0.0 & 0 \\
\end{tabular} & \begin{tabular}{l|l}
0.0 & $C$ \\
\end{tabular} & \begin{tabular}{l|l}
0.0 & 3 \\
\end{tabular} & \begin{tabular}{l|l|}
39.8 & \\
\end{tabular} & \begin{tabular}{|l|l|}
0.9 & 0 \\
\end{tabular} & \begin{tabular}{l|l}
0.4 & 0 \\
\end{tabular} & \begin{tabular}{l|l}
0.0 & 0 \\
\end{tabular} & \begin{tabular}{l|l}
0.1 & 0 \\
\end{tabular} & \begin{tabular}{l|l}
0.0 & 1 \\
\end{tabular} & \begin{tabular}{l|l}
1.0 & $\mathrm{C}$ \\
\end{tabular} & \begin{tabular}{|l|l|}
0.0 \\
\end{tabular} & 0.2 & 0.0 \\
\hline & 0.0 & & \begin{tabular}{|l|}
0.7 \\
\end{tabular} & 2. & \begin{tabular}{|l|}
0.9 \\
\end{tabular} & & 7.0 & 1. & 11.4 & 1 & \begin{tabular}{|l|l|}
8.2 & 2 \\
\end{tabular} & \begin{tabular}{l|l|l|}
2.5 & \\
\end{tabular} & \begin{tabular}{|l|l|}
0.0 & 0 \\
\end{tabular} & $\begin{array}{l}0.0 \\
0\end{array}$ & 0 & 1 & 1 & 0 & $\begin{array}{l}0.0 \\
0.0\end{array}$ & 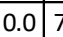 & $\begin{array}{l}79.6 \\
79\end{array}$ & \begin{tabular}{|l|l|}
1.7 & 0 \\
\end{tabular} & \begin{tabular}{l|l}
0.7 & 0 \\
\end{tabular} & $\begin{array}{l}0.0 \\
\end{array}$ & \begin{tabular}{l|l}
0.1 & 0 \\
\end{tabular} & \begin{tabular}{l|l}
0.0 & 2 \\
\end{tabular} & \begin{tabular}{l|l}
2.1 & $C$ \\
\end{tabular} & 0 & 4 & 0.0 \\
\hline & 45.0 & 4.0 & 2.0 & \begin{tabular}{|l|}
10.0 \\
\end{tabular} & 2.0 & \begin{tabular}{|l|}
0.1 \\
\end{tabular} & 3.5 & 1 & & 0 & 16 & \begin{tabular}{l|l}
6.1 & 1 \\
\end{tabular} & 1 & \begin{tabular}{l|l}
2.0 & 1 \\
\end{tabular} & \begin{tabular}{l|l|}
1.2 & 1. \\
\end{tabular} & 7 & 7 & \begin{tabular}{|l|l|}
5.0 & 3 \\
\end{tabular} & \begin{tabular}{l|l}
3.5 & 2 \\
\end{tabular} & \begin{tabular}{l|l|}
2.0 & 3 \\
\end{tabular} & \begin{tabular}{l|l}
39.8 & 5
\end{tabular} & \begin{tabular}{|l|l|}
5.0 & 2 \\
\end{tabular} & \begin{tabular}{l|l}
2.0 & 5 \\
\end{tabular} & \begin{tabular}{l|l}
5.0 & 2 \\
\end{tabular} & \begin{tabular}{l|l}
2.0 & 2 \\
\end{tabular} & 2.0 & \begin{tabular}{l|l}
.1 & 5 \\
\end{tabular} & $5.0|c|$ & 0.2 & 5.0 \\
\hline Only wind & 45.0 & 4.0 & 2.0 & \begin{tabular}{|l|}
10.0 \\
\end{tabular} & 2.0 & 2.0 & \begin{tabular}{|l|}
3.5 \\
\end{tabular} & \begin{tabular}{|l|}
11.0 \\
\end{tabular} & \begin{tabular}{|l|}
12.0 \\
\end{tabular} & \begin{tabular}{|l|}
13.0 \\
\end{tabular} & \begin{tabular}{|l|l|}
5.6 & 6 \\
\end{tabular} & \begin{tabular}{|l|l}
6.1 & 1 \\
\end{tabular} & \begin{tabular}{|l|l|}
1.2 & 2 \\
\end{tabular} & \begin{tabular}{l|l}
2.0 & 1
\end{tabular} & \begin{tabular}{l|l|}
1.2 & 1. \\
\end{tabular} & \begin{tabular}{l|l|}
1.2 & 1 \\
\end{tabular} & 18.5 & \begin{tabular}{|l|l|}
5.0 & 6 \\
\end{tabular} & \begin{tabular}{l|l}
6.0 & 2 \\
\end{tabular} & \begin{tabular}{l|l|}
2.0 \\
\end{tabular} & \begin{tabular}{l|c}
0.0 \\
\end{tabular} & \begin{tabular}{|l|l|}
0.0 & 0 \\
\end{tabular} & & \begin{tabular}{l|l}
0.0 & 0 \\
\end{tabular} & \begin{tabular}{l|l}
0.0 & 0
\end{tabular} & & & $\begin{array}{l}0.0 \\
0.0\end{array}$ & \begin{tabular}{|l|}
0.0 \\
\end{tabular} & 0.0 \\
\hline
\end{tabular}

APPENDIX C: LOWER AND UPPER BOUNDS FOR THE OPTIMIZED SCENARIO

\begin{tabular}{|c|c|c|c|c|c|c|c|c|c|c|c|c|c|c|c|c|c|c|c|c|c|c|c|c|c|c|c|c|c|c|}
\hline & \multicolumn{10}{|c|}{ Onshore wind } & \multicolumn{10}{|c|}{ Offshore wind } & \multicolumn{10}{|c|}{ PV } \\
\hline $\begin{array}{c}\text { Installation } \\
\text { limits (GW) }\end{array}$ & $\mathbf{D E}$ & $\mathbf{D K}$ & $\mathbf{E E}$ & $\mathbf{F I}$ & $\mathbf{L T}$ & $\mathbf{L V}$ & $\mathbf{N L}$ & $\mathbf{N O}$ & $\mathbf{P L}$ & $\mathbf{S E}$ & $\mathbf{D E}$ & $\mathbf{D K}$ & $\mathbf{E E}$ & $\mathbf{F I}$ & $\mathbf{L T}$ & $\mathbf{L V}$ & $\mathbf{N L}$ & $\mathbf{N O}$ & $\mathbf{P L}$ & $\mathbf{S E}$ & $\mathbf{D E}$ & $\mathbf{D K}$ & $\mathbf{E E}$ & $\mathbf{F I}$ & $\mathbf{L T}$ & $\mathbf{L V}$ & $\mathbf{N L}$ & $\mathbf{N O}$ & $\mathbf{P L}$ & $\mathbf{S E}$ \\
\hline Lower & 45.0 & 4.0 & 0.4 & 1.4 & 0.4 & 0.1 & 3.5 & 0.9 & 5.7 & 6.0 & 4.1 & 1.3 & 0.0 & 0.0 & 0.0 & 0.0 & 0.6 & 0.0 & 0.0 & 0.0 & 39.8 & 0.9 & 0.4 & 0.0 & 0.1 & 0.0 & 1.0 & 0.0 & 0.2 & 0.0 \\
\hline Upper & 71.0 & 6.5 & 2.0 & 10.0 & 2.0 & 2.0 & 15.0 & 11.0 & 12.0 & 13.0 & 20.0 & 6.1 & 1.2 & 2.0 & 1.2 & 1.2 & 18.5 & 5.0 & 6.0 & 2.0 & 59.7 & 5.0 & 2.0 & 5.0 & 2.0 & 2.0 & 11.5 & 5.0 & 5.0 & 5.0 \\
\hline
\end{tabular}

